\title{
O Cuidado Integral como uma Missão da Enfermagem: Uma Revisão Integrativa da Literatura
}

\author{
Aline Bezerra Sobrinho ${ }^{1}$; Anny Karinny Amaral de Vasconcelos ${ }^{2}$; Claudia Daniele Barros Leite-Salgueiro ${ }^{3}$
}

Resumo: O cuidar da enfermagem significa dedicação, zelo, atenção, se colocar no lugar do outro, seja em situações diversas, seja no contexto da vida, em coletividade, ou não. Também, quando da tentativa de diminuir a dor ou no desenvolvimento de uma prática humanizada e de qualidade, promovendo a saúde do ser. O cuidado integral é parte fundamental para a prática de uma enfermagem de qualidade, imprescindível, portanto, a formação de enfermeiros capacitados. Objetivo: Identificar o cuidado integral como missão da enfermagem. Método: Tratase de uma revisão integrativa, método que permite reunir, sistematizar e ordenar os resultados de pesquisas sobre cuidados em enfermagem. Resultados e Discussão: Observou-se que a maioria dos estudos enfatizam a importância do cuidar de forma integral, enquanto outros se antecipam enquanto à forma de conhecer cientificamente o cuidar. A amostra final é composta por 10 artigos. Conclusão: As melhores formas de desenvolver/prestar o cuidado é de forma holística e, percebendo a real necessidade do paciente/cliente.

Palavras-chaves: Cuidado; Enfermagem; Arte do cuidado.

\section{Integral Care as a Mission of Nursing: An Integrative Review of the Literature}

\begin{abstract}
Nursing care means dedication, zeal, care, putting oneself in another's place, whether in different situations, in the context of life, in a community, or not. Also, when trying to reduce pain or developing a humanized and quality practice, promoting the health of the being. Integral care is a fundamental part of the practice of quality nursing, which is essential, therefore, for the training of trained nurses. Objective: To identify integral care as a nursing mission. Method: It is an integrative review, a method that allows to gather, systematize and order the results of research on nursing care. Results and Discussion: It was observed that most of the studies emphasize the importance of caring in an integral way, while others anticipate the way of scientifically knowing caring. The final sample consists of 10 articles Conclusion: The best ways to develop / deliver care is in a holistic way, and realizing the real need of the patient / client.
\end{abstract}

Keywords: Care; Nursing; Care art.

\footnotetext{
${ }^{1}$ Discente do Curso de Bacharelado em Enfermagem do Instituto Federal de Educação, Ciência e Tecnologia de Pernambuco (IFPE) - Campus Pesqueira. Contato: aline_miguelarcanjo@ hotmail.com .

${ }^{2}$ Discente do Curso de Bacharelado em Enfermagem do Instituto Federal de Educação, Ciência e Tecnologia de Pernambuco (IFPE) - Campus Pesqueira. Contato: annykarinny@ hotmail.com.

${ }^{3}$ Doutora em Psicologia Clínica pela Universidade Católica de Pernambuco (UNICAP), Mestra em Ciências da Saúde pela Universidade de Pernambuco (UPE), Pós Graduada (Lato Sensu) em Saúde Coletiva pela mesma Universidade. Psicóloga formada pela Universidade Católica de Pernambuco (UNICAP). Docente do curso Bacharelado em Enfermagem do Instituto Federal de Educação, Ciência e Tecnologia de Pernambuco (IFPE) - Campus Pesqueira. Coordenadora de Projetos de Pesquisa e Extensão, na linha de Cuidado à Pessoa Idosa e em Educação. Contato: claudia.leite@ pesqueira.ifpe.edu.br.
} 


\section{Introdução}

Cuidar implica colocar-se no lugar do outro, comumente em situações diversas, seja no aspecto pessoal ou social. É uma forma de permanecer ligado ao outro, no tocante a questões especiais da vida do nascimento e da morte. $\mathrm{O}$ ato de cuidar é um ato de amor ao próximo, de valorização da vida como o bem mais precioso que existe.

O conceito de cuidado é amplo e abrange diversos significados. Pode-se dizer que o cuidado significa solicitude, dedicação, preocupação, atenção, zelo. O cuidado também surge na promoção, na preservação e na reabilitação da saúde de uma pessoa e se expressa no contexto individual ou coletivo (SAVIETO, LEÃO, 2016).

A relação de cuidado se caracteriza pela relação interpessoal, onde há de um lado um indivíduo que manifesta comportamentos de cuidar e de outro, um indivíduo que necessita de cuidados. A relação entre os dois lados é marcada pela expressão de consideração, interesse, respeito, confiança, entre outros aspectos (CASTRO, PEREIRA, 2011).

O cuidado integral é parte fundamental para a prática de uma enfermagem compromissada com a qualidade. Imprescindível, portanto, a formação de enfermeiros capacitados em práticas cuidadoras.

$\mathrm{O}$ cuidado em enfermagem tem em vista proteger, promover e preservar o homem, com a visão de colocar-se no lugar do outro, estreita-se as ideias do humanismo pela capacidade humana de ajudar e de se solidarizar para com o próximo. Assim, prestar cuidado, seja na forma pessoal ou social, é um valor que integra os identificadores da profissão da enfermagem (SOUZA et al., 2005).

Dito isto, o presente artigo realiza uma revisão integrativa que tem como objetivo identificar o cuidado integral como missão da enfermagem. Para isso, analisa artigos que demonstram as melhores formas de desenvolver/prestar o cuidado de forma holística, buscando perceber a real necessidade do paciente/cliente.

Ao discutir o cuidado integral como missão da enfermagem, este artigo busca dar uma pequena contribuição acadêmica ao debate em torno do assunto. Faz-se necessário evidenciar o cuidado integral como prática da enfermagem, a fim de que se possa formar enfermeiros humanizados e compromissados com a valorização da vida. 


\section{Marco Teórico}

O modelo de assistência instituído pelo Sistema Único de Saúde (SUS) recomenda que o cuidado integral seja competência dos serviços de saúde nos diversos níveis de atenção. A Política Nacional de Humanização (PNH) que busca dar maior efetividade aos princípios do SUS - no tocante a práticas de atenção e gestão - aponta para a humanização, a comunicação, a criação de elos solidários e a valorização das relações de afeto (HUMANIZA SUS, 2013).

A PNH indica elementos que integram o cuidado integral, sendo precedente o acolhimento, que traz em si a ideia de resolutividade e, também, de responsabilização (CASTRO, PEREIRA, 2011).

Dada as recomendações do SUS faz-se necessário então, a criação de ambientes de trabalho onde as relações de cuidado sejam cultivadas. Desse modo, o enfermeiro se habilita a tarefa, pois é o profissional que administra, planeja, organiza, coordena, executa e avalia a assistência em enfermagem. Ademais articula ações educativas de promoção e preservação da saúde. O enfermeiro no exercício digno da profissão acolhe o indivíduo, orienta, acompanha seu estado de saúde e presta cuidados (APOLINÁRIO, 2013).

A relação de cuidado é uma relação de empatia, estabelecida entre a pessoa que cuida e a que é cuidada. O cuidar se realiza a partir do conhecimento das necessidades do outro. Dentro de certos limites, o sujeito cuidador se aproxima da realidade do sujeito que é cuidado, para compreender quais são suas reais necessidades. Ao acolher o outro e respeitá-lo, reafirma-se sua a condição de cuidador (SAVIETO, LEÃO, 2016).

O ambiente de cuidado é propicio ao bem estar das pessoas. Quando bem executado possibilita melhora ou preservação da qualidade de vida das pessoas que dele dependem. Neste sentido, cabe ao enfermeiro a construção de um ambiente de cuidado em que o paciente se sinta amparado (WALDOW, 2014).

O trabalho do enfermeiro é propício ao alcance do cuidado integral. Este não pode ser entendido como uma simples ação técnico-assistencial, desprovida de elementos humanizadores tais como o afeto e o acolhimento (CASTRO, PEREIRA, 2011).

Anteriormente, o modelo de assistência, do cuidar era basicamente centrado na doença em que a principal porta de entrada para o serviço de saúde era o hospital, estes serviços prestados na atenção básica eram considerados pouco qualificados e despreparados para o atendimento às necessidades de saúde das comunidades, onde as ações de prevenção e promoção a saúde não tinha a devida ênfase (SAVIETO, LEÃO, 2016). 
O cuidar em enfermagem adquire maior atenção a partir do desenvolvimento da Teoria de Enfermagem na década de 1970, com os trabalhos da enfermeira brasileira Wanda de Aguiar Horta. Baseada na teoria da Motivação Humana de Maslow, de onde extrai o conceito de necessidades básicas humanas, Horta desenvolve sua teoria. Nela, a enfermagem é compreendida como um conjunto de ações inter-relacionadas e sistematizadas com o intuito de assistir ao ser humano e o enfermeiro é "gente que cuida de gente" (HORTA, 1974).

Nesse contexto, o cuidar/assistir em enfermagem, configura-se como fazer pelo outro aquilo que ele não pode fazer a si mesmo, auxiliar quando o outro está impossibilitado de se autocuidar (OLIVEIRA, 2012).

Interligando o conceito de necessidades básicas humanas ao de cuidado integral, tem-se a ideia de que uma necessidade não satisfeita interfere em todas as outras e expõe o indivíduo de modo a deixá-lo mais suscetível ao adoecimento (SOUSA, BERNARDINO, 2017).

A Teoria da Enfermagem de Horta ajudou a estabelecer um referencial próprio da Enfermagem, trouxe consigo alguns princípios como o que considera o cuidado de enfermagem preventivo e curativo ou o que reconhece o autocuidado humano; influenciou gerações de enfermeiros brasileiros e ainda se mostra atual no ensino e na prática de enfermagem (SANTANA et. al, 2012).

Atualmente, há uma gama de tendências mundiais quando se trata de teorias de enfermagem que se ampliam muito além do cuidado biológico. No Brasil, enfermeiros tendem a escolher a prática do cuidar de forma holística, que atenderá as necessidades dos pacientes/clientes nos mais diversos aspectos causando satisfação de quem proporciona o cuidado como também de quem o recebe (OLIVEIRA, 2012).

São diversas as teorias que abordam o cuidado. A Teoria do Cuidado Humano desenvolvida por Margaret Jean Watson, compreende o cuidado por meio de uma relação transpessoal, em que o cuidado se constrói a partir da capacidade de entender o sentimento do outro. Essa teoria entende que o desenvolvimento do comportamento empático se relaciona com o preocupar-se com o estado do sofrimento alheio, assim estreitando as relações interpessoais por meio de um vínculo afetivo e de competência comunicacional (SAVIETO, LEÃO, 2016).

Entre outros autores que trabalham com linhas de teoria de enfermagem, pode-se citar:Teoria Humanística de Paterson e Zderad, que tem como princípio retomar a grandeza humanística do cuidado; Leininger, com a Teoria do Cuidado Cultural que vem sendo empregada pela Enfermagem brasileira por aprovar o entendimento dos fenômenos de saúde e 
doença que transpassam o vivido de pessoas e/ou grupos populacionais; A Teoria do Autocuidado de Orem, quepreza por práticas e atitudes que ofertem as pessoas e/ou grupos populacionais o autocuidado, principalmente no que se diz respeito as condições crônicas de doença que têm requisitado dos indivíduos mais dias de tratamento, assim a necessidade do uso de tecnologias no domicílio do doente e a reestruturação do seu cotidiano, como maneiras de cuidado de si (SAVIETO e LEÃO, 2016).

Os teóricos citados anteriormente e suas respectivas teorias de enfermagem tem em comum, o cuidar de enfermagem para com o outro, no qual evidenciam, a importância de transcender o corpo físico no ato do cuidar. Ou seja, cuidar de forma que contemple todos os aspectos que o ser precisa: físico, psíquico, emocional, social. Propiciando a cura, o bem-estar, a prevenção e a promoção da saúde do ser com também da coletividade.

A idéia de um cuidado integral como um todo é uma diretriz da Enfermagem. A integralidade da assistência ofertada deve abranger não só aspectos físicos e mentais como também sociais. Na internação pediátrica, por exemplo, o cuidar integral e diário de crianças doentes sensibilizam a equipe de saúde para problemas que costumam não só afetá-las, como também suas famílias (CASTRO, PEREIRA, 2011).

Há teóricos que traçam outras linhas de inter-relação para o cuidado, como: Florence e Rogers que relaciona o ser e o ambiente; Bener traz a "proficiência" do enfermeiro quando associa o conhecimento teórico e a prática, ou seja, conhecimento teórico - "saber o quê", o conhecimento prático - "saber como" (SAVIETO e LEÃO, 2016).

$\mathrm{Na}$ enfermagem se faz necessário o cuidar de forma humanizada, para isso a escuta é um dos fatores de muita importância para uma boa relação profissional-usuário. No entanto, deve ser capaz de respeitar a individualidade de cada ser, como também, valorizar as crenças atentando para a comunicação. A enfermagem deve também orientar os cuidadores de forma clara, sejam, cuidadores de idosos ou não para que possam desempenhar o cuidado com responsabilidade e dinamismo (CHERNICHAROI, FREITAS, FERREIRA, 2013).

Daí então se faz necessário o conhecer científico mais o prazer de cuidar do outro, tendo assim um desenvolvimento de uma prática de qualidade e consequentemente, satisfação para ambas as partes, profissionais e pacientes proporcionando o prazer da cura e/ou amenização da dor e do sofrimento do outro (CHRISTOVAM, PORTO, OLIVEIRA, 2012). 


\section{Metodologia}

O presente artigo apresenta uma revisão integrativa da literatura sobre o cuidado em enfermagem. Este método permite a reunião, a avaliação e sinterização dos resultados de pesquisas, possibilitando novas abordagens e perspectivas sobre o assunto revisado. Além do mais, oferece o rigor exigível na pesquisa científica e a legitimidade das evidências estabelecidas (LAKATOS; MARCONI, 2010).

A revisão integrativa da literatura define o pensamento atual sobre uma temática específica. É um método que analisa de forma crítica, estudos anteriores sobre a temática selecionando-os de acordo com as fases organizativas que permitem explorar e apreciar os dados coletados (SOUZA, SILVA, CARVALHO, 2010).

A triagem de artigos de saúde amparados em evidências científicas comprovadas tornase indispensável em razão da alta demanda de informações na área. Neste sentido, a revisão integrativa possibilita uma sistematização dos resultados mais expressivos das pesquisas. Cumprindo as seguintes etapas: pergunta condutora; coleta de dados, classificação dos dados, análise e discussão dos estudos incluídos, e resultados finais (CROSSETTI, 2012).

O presente artigo estabeleceu a pergunta condutora: Qual a importância do cuidado integral como missão na assistência de enfermagem?

Em razão do quantitativo de artigos da área de saúde indexados. Elegeram-se bases de dados, locais na rede mundial de computadores (internet) que contemplam estudos primários, assim como também artigos nas temáticas relacionadas à enfermagem (SOUZA, CABRAL, LEITEet al., 2018).

Os artigos estavam disponíveis nas bases de dados do Portal Regional da Biblioteca Virtual de Saúde (BVS),Literatura Latino-Americana em Ciências de Saúde (LILACS),e na ScientificElectronic Library Online (SciELO).

Assim, fez uso dos seguintes descritores: Cuidado; Enfermagem; Arte do Cuidar. Tais descritores, no idioma português, foram organizados de diferentes modos com o objetivo de ampliar a busca pelos estudos. Variações terminológicas, bem como sinônimos também foram considerados.

Esta pesquisa também fez uso dos operadores booleanos: expressões AND/OR/AND NOT utilizadas para fazer associações de palavras durante a pesquisa. Tais operadores combinam duas ou mais palavras/assuntos no(s) campo(s) de busca para ocorrência simultânea de assuntos, permitindo aprimorar a pesquisa (SOUZA, CABRAL, LEITE et al, 2018).

Desse modo, os descritores foram combinados da seguinte maneira: cuidado and enfermagem; arte and cuidar; enfermagem and cuidado. 
Na seleção dos artigos científicos, foram utilizados filtros para pesquisa. Os critérios de inclusão foram artigos originais completos, publicados a partir de 2012, em periódicos nacionais e no idioma português, indexados nos bancos de dados, que abordassem os descritores selecionados. Artigos incompletos ou duplicados, que não apresentavam clareza, os publicados em língua estrangeira ou que não condiziam com os descritores selecionados foram excluídos.

A coleta de dados ocorreu entre os meses de julho e agosto de 2018, atendendo o preenchimento de um quadro com as seguintes variáveis: número de referência do artigo, título, nome do autor, ano de publicação, periódico de publicação; qualificação no sistema Qualis da Coordenação de Aperfeiçoamento de Ensino Superior (CAPES); tipo de estudo; nível de evidência; objetivos do estudo e resultados.

A classificação hierárquica das evidências, sistema que visa fortalecer o processo de Prática Baseada em Evidências, serviu como base para avaliação de cada estudo. Utilizada para avaliação de pesquisas ou outras fontes de informação, acaba por oferecer subsídios ao enfermeiro na avaliação crítica de resultados provenientes de pesquisas e na tomada de decisão sobre a incorporação das evidências à prática clínica (GALVÃO, 2016).

A qualidade das evidências é dividida em seis níveis: o nível I corresponde a metaanálise de estudos controlados e randomizados; o nível II, estudos individuais experimentais; o nível III, engloba estudos quase-experimentais a exemplo de estudo sem randomização com grupo único pré e pós-teste, séries temporais ou caso-controle; o nível IV, estudos descritivos com delineamento não-experimental como pesquisa descritiva correlacional e qualitativa ou estudos de caso; o nível V, relatos de casos ou dados obtidos de forma sistemática, de qualidade verificável ou dados de avaliação de programas; o nível VI, opiniões de especialistas respeitáveis fundadas na competência clínica ou de comitês de especialistas, incluindo interpretações de informações não baseadas em pesquisas (GALVÃO, 2016).

Os resultados foram apresentados de forma descritiva, com auxílio de tabelas e gráficos. Inicialmente foram encontrados 30 artigos nas bases de dados, por critérios de exclusão 20 amostras encontradas foram descartadas sobrando, portanto, 10 artigos como amostra final. Após a coleta de dados procedeu-se a análise dos resultados. Assim, apresentou-se os principais referenciais teóricos que analisam o tema do cuidado integral em enfermagem. 


\section{Resultado e Discussão}

Foram encontrados 26 (vinte e seis) estudos de acordo com os descritores selecionados em língua portuguesa. Sendo que 16 foram excluídos por estarem repetidos ou não coincidir com os descritores referidos para a pesquisa, restando 10 (dez) para leitura na íntegra. Para categorização, eles foram organizados em um código de identificação de $\mathrm{A}-01$ até $\mathrm{A}-10.27$ estudos ou $100 \%$ das publicações foram produzidos no Brasil entre os anos de 2009 e 2016, conforme indicado na tabela 1.

Tabela 1. Catalogação das publicações encontradas de acordo com o ano de publicação.

\begin{tabular}{cccc} 
Ano & Código do Artigo & Número de estudos publicados & \% \\
\hline 2012 & A-02, A-04, A-07, A-08, A-10 & 05 & 50 \\
\hline 2013 & A- 03 & 01 & 10 \\
\hline 2014 & A-01 & 01 & 10 \\
\hline 2015 & A-09 & 01 & 10 \\
\hline 2016 & A-05, A-06 & 02 & 20 \\
\hline 2017 & ------ & ------ & -- \\
\hline 2018 & ------ & ------- & -- \\
\hline & & 10 & 100 \\
\hline
\end{tabular}

Fonte: Pesquisa dos autores, 2017.

Observa-se a ausência de um padrão no número de estudos publicados ao longo dos anos. Verifica-se que o ano de 2012 foi o mais expressivo em publicações. Tais estudos foram elencados no Quadro 1.

Quadro 1. Caracterização das publicações encontradas.

\begin{tabular}{|c|c|c|c|c|c|c|c|c|}
\hline $\begin{array}{c}\text { Código } \\
\text { do } \\
\text { artigo } \\
\end{array}$ & $\begin{array}{l}\text { Título do } \\
\text { artigo }\end{array}$ & Autores & $\begin{array}{c}\text { Ano } \\
\text { de } \\
\text { Publicação }\end{array}$ & $\begin{array}{c}\text { Nome do } \\
\text { Periódico/ } \\
\text { Revista } \\
\end{array}$ & $\begin{array}{l}\text { Qualis } \\
\text { Capes }\end{array}$ & $\begin{array}{c}\text { Tipo de } \\
\text { estudo/Nível } \\
\text { de evidência }\end{array}$ & $\begin{array}{l}\text { Objetivo do } \\
\text { estudo }\end{array}$ & Resultados \\
\hline A-01 & $\begin{array}{l}\mathrm{O} \text { cuidar em } \\
\text { quimioterapia } \\
\text { : a percepção } \\
\text { da equipe de } \\
\text { enfermagem }\end{array}$ & $\begin{array}{c}\text { LIMA, E, F, } \\
\text { A; COELHO } \\
\text { SO, LEITE } \\
\text { FMC, et al. }\end{array}$ & 2014 & $\begin{array}{l}\text { Revista de } \\
\text { pesquisa } \\
\text { Cuidado é } \\
\text { fundamenta } \\
\text { l online - } \\
\text { UFRJ }\end{array}$ & B3 & $\begin{array}{c}\text { Estudo } \\
\text { descritivo } \\
\text { com } \\
\text { abordagem } \\
\text { qualitativa } \\
\text { /IV }\end{array}$ & $\begin{array}{l}\text { Conhecer a } \\
\text { percepção da } \\
\text { equipe de } \\
\text { enfermagem } \\
\text { de uma } \\
\text { unidade de } \\
\text { quimioterapia } \\
\text { acerca } \\
\text { docuidado }\end{array}$ & $\begin{array}{l}\text { O cuidar exige muito } \\
\text { mais do que } \\
\text { conhecimentos técnico } \\
\text { científicos, requer a } \\
\text { compreensão a fundo de } \\
\text { sua individualidade, a } \\
\text { partir de um } \\
\text { relacionamento } \\
\text { interpessoal de } \\
\text { valorização da pessoa } \\
\text { humana, contribuindo, } \\
\text { consequentemente, com } \\
\text { o processo de } \\
\text { humanização do } \\
\text { cuidado. }\end{array}$ \\
\hline A-02 & & & 2012 & $\begin{array}{c}\text { Revista } \\
\text { Ciências e } \\
\end{array}$ & B1 & $\begin{array}{c}\text { Teoria } \\
\text { fundamentada }\end{array}$ & $\begin{array}{l}\text { Compreender } \\
\text { o significado }\end{array}$ & $\begin{array}{l}\text { Um novo modelo } \\
\text { assistencial se }\end{array}$ \\
\hline
\end{tabular}




\begin{tabular}{|c|c|c|c|c|c|c|c|c|}
\hline & $\begin{array}{l}\text { Significado } \\
\text { da atuação da } \\
\text { equipe da } \\
\text { estratégia de } \\
\text { saúde } \\
\text { da família em } \\
\text { uma } \\
\text { comunidade } \\
\text { socialmente } \\
\text { vulnerável }\end{array}$ & $\begin{array}{l}\text { BACKES, } \\
\text { D.S; } \\
\text { STEIN, M.T } \\
\text { BACKES, A }\end{array}$ & & $\begin{array}{c}\text { Saúde } \\
\text { Coletiva }\end{array}$ & & $\begin{array}{c}\text { nos dados } \\
\text { (tfd)/ IV }\end{array}$ & $\begin{array}{l}\text { da atuação } \\
\text { profissional } \\
\text { de uma } \\
\text { equipe ESF } \\
\text { em uma } \\
\text { comunidade } \\
\text { socialmente } \\
\text { vulnerável }\end{array}$ & $\begin{array}{l}\text { desenvolve, em suma, } \\
\text { mediante a } \\
\text { reorganização da prática } \\
\text { de atenção à saúde, } \\
\text { intermediada pela } \\
\text { multiplicidade de } \\
\text { relações, interações e } \\
\text { associações complexas } \\
\text { que ocorrem no contexto } \\
\text { familiar e social }\end{array}$ \\
\hline A-03 & $\begin{array}{c}\text { Humanização } \\
\text { no cuidado de } \\
\text { enfermagem: } \\
\text { contribuição } \\
\text { ao } \\
\text { debate sobre a } \\
\text { política } \\
\text { nacional de } \\
\text { humanização }\end{array}$ & $\begin{array}{l}\text { CHERNICH } \\
\text { AROI, I. M.; } \\
\text { FREITAS, } \\
\text { F.D.S.; } \\
\text { FERREIRA, } \\
\text { M. A. }\end{array}$ & 2013 & $\begin{array}{c}\text { Revista } \\
\text { Brasileira } \\
\text { de } \\
\text { Enfermage } \\
\text { m }\end{array}$ & A2 & $\begin{array}{c}\text { Estudo } \\
\text { descritivo } \\
\text { com } \\
\text { abordagem } \\
\text { qualitativa/IV }\end{array}$ & $\begin{array}{c}\text { Identificar e } \\
\text { analisar os } \\
\text { elementos } \\
\text { que } \\
\text { conformam as } \\
\text { representaçõe } \\
\text { s de } \\
\text { profissionais } \\
\text { de } \\
\text { enfermagem e } \\
\text { usuários } \\
\text { sobre a } \\
\text { humanização } \\
\text { no cuidado; e } \\
\text { discutir } \\
\text { estratégias } \\
\text { que } \\
\text { contribuam } \\
\text { para a } \\
\text { implementaçã } \\
\text { o da Política } \\
\text { Nacional de } \\
\text { Humanização }\end{array}$ & $\begin{array}{c}\text { O debate com os sujeitos } \\
\text { envolvidos no processo } \\
\text { apresenta-se como } \\
\text { estratégia para o alcance } \\
\text { dos preceitos da Política } \\
\text { Nacional de } \\
\text { Humanização. }\end{array}$ \\
\hline A-04 & $\begin{array}{l}\text { História do } \\
\text { cuidado a } \\
\text { mulher na } \\
\text { maternidade } \\
\text { Carmela } \\
\text { Dutra, } \\
\text { florianopolis- } \\
\text { sc, brasil } \\
(1956-2001)\end{array}$ & $\begin{array}{l}\text { GREGORIO, } \\
\text { P.V.R; } \\
\text { PADILHA, } \\
\text { S.C.M.I }\end{array}$ & 2012 & $\begin{array}{c}\text { Revista } \\
\text { Brasileira } \\
\text { de } \\
\text { Enfermage } \\
\text { m }\end{array}$ & A2 & $\begin{array}{c}\text { Pesquisa } \\
\text { qualitativa } \\
\text { com } \\
\text { abordagem } \\
\text { sócio- } \\
\text { histórica/III }\end{array}$ & $\begin{array}{c}\text { Analisar as } \\
\text { práticas de } \\
\text { cuidado } \\
\text { desenvolvidas } \\
\text { pelas } \\
\text { enfermeiras a } \\
\text { mulher na } \\
\text { Maternidade } \\
\text { Carmela } \\
\text { Dutra, } \\
\text { de } \\
\text { Florianopolis, } \\
\text { Santa } \\
\text { Catarina, no } \\
\text { período de } \\
\text { 1956 a 2001 }\end{array}$ & $\begin{array}{l}\text { O cuidado prestado à } \\
\text { mulher na maternidade } \\
\text { foi exercido por } \\
\text { religiosas e parteiras, por } \\
\text { enfermeiras leigas e por } \\
\text { enfermeiras obstétricas, } \\
\text { numa trajetória que vai } \\
\text { do cuidado laico ao } \\
\text { profissional, entrelaçado } \\
\text { por relações de saber- } \\
\text { poder demarcadas por } \\
\text { lutas e resistências ao } \\
\text { poder médico } \\
\text { hegemônico da época. }\end{array}$ \\
\hline A-05 & $\begin{array}{c}\text { Educação } \\
\text { permanente } \\
\text { no contexto } \\
\text { hospitalar : a } \\
\text { experiência } \\
\text { que } \\
\text { ressignifica o } \\
\text { cuidado em } \\
\text { enfermagem }\end{array}$ & $\begin{array}{l}\text { ROBERTA } \\
\text { FORTES } \\
\text { SANTIAGO; } \\
\text { MARIA } \\
\text { HELENA } \\
\text { BARROS } \\
\text { ARAÚJO } \\
\text { LUZ }\end{array}$ & 2016 & $\begin{array}{c}\text { Trabalho } \\
\text { Educação e } \\
\text { Saúde }\end{array}$ & B3 & $\begin{array}{c}\text { Estudo } \\
\text { descritivo } \\
\text { com } \\
\text { abordagem } \\
\text { qualitativa/IV }\end{array}$ & $\begin{array}{c}\text { Analisar } \\
\text { experiências } \\
\text { que } \\
\text { constituíram } \\
\text { esse processo, } \\
\text { os sentidos } \\
\text { dessa } \\
\text { formação e as } \\
\text { mudanças } \\
\text { decorridas no } \\
\text { desenvolvime } \\
\text { nto do } \\
\text { cuidado de } \\
\text { enfermagem } \\
\end{array}$ & $\begin{array}{l}\text { A participação das } \\
\text { enfermeiras no programa } \\
\text { resultou em abertura } \\
\text { para diversas mudanças } \\
\text { no seu processo de } \\
\text { trabalho e na modelagem } \\
\text { de ensino-aprendizagem }\end{array}$ \\
\hline A-06 & $\begin{array}{c}\text { Integralidade } \\
\text { do cuidado: } \\
\text { concepções e } \\
\text { práticas } \\
\text { de docentes } \\
\text { de graduação } \\
\text { em } \\
\text { enfermagem } \\
\text { do estado de } \\
\text { Goiás }\end{array}$ & $\begin{array}{l}\text { SANTANA, } \\
\text { F.R. et.al. }\end{array}$ & 2016 & $\begin{array}{c}\text { Revista } \\
\text { eletrônica } \\
\text { de } \\
\text { enfermage } \\
\text { m }\end{array}$ & B1 & $\begin{array}{c}\text { Estudo } \\
\text { descritivo- } \\
\text { exploratório,/ } \\
\text { IV }\end{array}$ & $\begin{array}{c}\text { Analisar as } \\
\text { concepções } \\
\text { de } \\
\text { integralidade } \\
\text { do cuidado } \\
\text { presentes nos } \\
\text { discursos dos } \\
\text { docentes e as } \\
\text { estratégias } \\
\text { utilizadas }\end{array}$ & $\begin{array}{l}\text { Devem ser valorizadas } \\
\text { as contribuições das } \\
\text { outras áreas do } \\
\text { conhecimento, como as } \\
\text { ciências humanas e } \\
\text { sociais, na perspectiva de } \\
\text { trabalhos } \\
\text { transdisciplinares e } \\
\text { transetoriais, enfatizando } \\
\text { tecnologias leves } \\
\text { (diálogo) e tecnologias }\end{array}$ \\
\hline
\end{tabular}




\begin{tabular}{|c|c|c|c|c|c|c|c|c|}
\hline & & & & & & & $\begin{array}{c}\text { para a } \\
\text { apreensão } \\
\text { da } \\
\text { integralidade } \\
\text { pelos } \\
\text { discentes }\end{array}$ & $\begin{array}{l}\text { leves duras (corpo de } \\
\text { conhecimento das } \\
\text { profissões). }\end{array}$ \\
\hline A-07 & $\begin{array}{l}\text { (RE)Significa } \\
\text { ndo os } \\
\text { projetos } \\
\text { cuidativos da } \\
\text { enfermagem } \\
\text { à luz das } \\
\text { necessidades } \\
\text { em saúde da } \\
\text { população }\end{array}$ & $\begin{array}{l}\text { OLIVEIRA, } \\
\text { C.M.A. }\end{array}$ & 2012 & $\begin{array}{c}\text { Revista } \\
\text { Brasileira } \\
\text { de } \\
\text { Enfermage } \\
\text { m }\end{array}$ & A2 & $\begin{array}{c}\text { Estudo } \\
\text { descritivo } \\
\text { com } \\
\text { abordagem } \\
\text { qualitativa/IV }\end{array}$ & $\begin{array}{l}\text { Adotar uma } \\
\text { concepção de } \\
\text { saúde e } \\
\text { doença capaz } \\
\text { de interligar } \\
\text { aspectos } \\
\text { individuais e } \\
\text { coletivos. }\end{array}$ & $\begin{array}{l}\text { Ressignificar o cuidado } \\
\text { em saúde e, em especial, } \\
\text { os projetos cuidativos da } \\
\text { Enfermagem à luz das } \\
\text { necessidades em saúde } \\
\text { da população requer } \\
\text { adotar uma concepção de } \\
\text { saúde e doença capaz de } \\
\text { interligar aspectos } \\
\text { individuais e coletivos }\end{array}$ \\
\hline A-08 & $\begin{array}{l}\text { O olhar da } \\
\text { enfermagem } \\
\text { sobre as } \\
\text { práticas de } \\
\text { cuidado de } \\
\text { famílias } \\
\text { rurais à } \\
\text { pessoa com } \\
\text { câncer }\end{array}$ & $\begin{array}{c}\text { ZILLMIER, } \\
\text { V.J.G; } \\
\text { SCHWARTZ } \\
\text {,E.; } \\
\text { MUNIZ.R.M }\end{array}$ & 2012 & $\begin{array}{l}\text { Revista da } \\
\text { escola de } \\
\text { enfermage } \\
\text { m USP }\end{array}$ & A2 & $\begin{array}{c}\text { Estudo } \\
\text { descritivo } \\
\text { com } \\
\text { abordagem } \\
\text { qualitativa/IV }\end{array}$ & $\begin{array}{l}\text { Identificar as } \\
\text { práticas de } \\
\text { cuidados das } \\
\text { famílias } \\
\text { rurais que } \\
\text { vivenciam o } \\
\text { cuidar da } \\
\text { pessoa com } \\
\text { câncer }\end{array}$ & $\begin{array}{l}\text { O carinho, o amor, a } \\
\text { proteção, a união } \\
\text { familiar, a fé, o estar } \\
\text { junto, a preocupação } \\
\text { com a alimentação } \\
\text { descrevem o cuidar e } \\
\text { constituem-se como } \\
\text { práticas de cuidado das } \\
\text { famílias rurais à pessoa } \\
\text { com câncer }\end{array}$ \\
\hline A-09 & $\begin{array}{l}\text { Significado } \\
\text { do cuidado } \\
\text { para } \\
\text { enfermagem } \\
\text { de centro } \\
\text { cirúrgico }\end{array}$ & $\begin{array}{c}\text { SALBERGO, } \\
\text { C.; } \\
\text { DORNELLE } \\
\text { S, } \\
\text { C.S.; } \\
\text { BITENCOUR } \\
\text { T, } \\
\text { P.T.G }\end{array}$ & 2015 & $\begin{array}{c}\text { Revista } \\
\text { Rene }\end{array}$ & B1 & $\begin{array}{c}\text { Estudo } \\
\text { descritivo } \\
\text { com } \\
\text { abordagem } \\
\text { qualitativa/IV }\end{array}$ & $\begin{array}{c}\text { Conhecer o } \\
\text { significado do } \\
\text { cuidado para } \\
\text { os técnicos de } \\
\text { enfermagem } \\
\text { que laboram } \\
\text { no Centro } \\
\text { Cirúrgico de } \\
\text { um hospital } \\
\text { geral da } \\
\text { fronteira } \\
\text { oeste do Rio } \\
\text { Grande do } \\
\text { Sul/Brasil }\end{array}$ & $\begin{array}{l}\text { No centro cirúrgico o } \\
\text { cuidado é uma atividade } \\
\text { com múltiplos aspectos, } \\
\text { envolvendo pacientes, } \\
\text { familiares e equipe. Os } \\
\text { significados valorizados } \\
\text { pelos profissionais } \\
\text { revelam o desprender-se } \\
\text { do tecnicismo para } \\
\text { valorizar questões } \\
\text { psicológicas, sociais e } \\
\text { afetivas do cuidado. }\end{array}$ \\
\hline A-10 & $\begin{array}{l}\text { Práticas de } \\
\text { educação em } \\
\text { saúde para } \\
\text { cuidadores de } \\
\text { idosos: um } \\
\text { olhar da } \\
\text { enfermagem } \\
\text { na } \\
\text { perspectiva } \\
\text { freireana }\end{array}$ & $\begin{array}{c}\text { SANTIAGO, } \\
\text { R.F } \\
\text { LUZ ,M. H. } \\
\text { B. A }\end{array}$ & 2012 & $\begin{array}{c}\text { Revista } \\
\text { Rene }\end{array}$ & B1 & $\begin{array}{c}\text { Estudo } \\
\text { descritivo } \\
\text { com } \\
\text { abordagem } \\
\text { qualitativa/IV }\end{array}$ & $\begin{array}{l}\text { Cuidadores } \\
\text { de } \\
\text { idosos que, } \\
\text { para } \\
\text { exercerem o } \\
\text { cuidado, } \\
\text { necessitam } \\
\text { ser orientados } \\
\text { e } \\
\text { acompanhado } \\
\text { s por meio de } \\
\text { atividades } \\
\text { educativas }\end{array}$ & $\begin{array}{l}\text { A incorporação das } \\
\text { ideias freireanas, } \\
\text { principalmente pelos } \\
\text { enfermeiros, pode } \\
\text { proporcionar aos } \\
\text { cuidadores de idosos a } \\
\text { conscientização, o } \\
\text { desenvolvimento de uma } \\
\text { reflexão crítica e, por sua } \\
\text { vez, o desempenho } \\
\text { melhor de suas ações. }\end{array}$ \\
\hline
\end{tabular}

Fonte: Pesquisa dos autores, 2017.

As publicações selecionadas abordam o cuidar como de fundamental importância para que seja evidenciado desde à graduação até o ato do cuidar na prática diária. Observa-se no quadro 1 que os artigos A-01 e A-08 evidenciam o cuidado voltado para pacientes oncológicos. Por sua vez, os artigos A-05, A-06 tratam que se deve apreender o cuidar como imprescindível,desde os cursos de graduação onde o docente possa incutir a relevância desse atopara uma prática segura e eficaz. Os artigos A-02 e A-07 fazem jus a compreensão da atuação da equipe de uma ESF socialmente vulnerável, como também o cuidar em coletividade, 
enquanto o artigo A-03 faz uma abordagem sobre a contribuição de estratégias da forma do cuidar como contribuição para elaboração de Políticas de Humanização.

O artigo A-04 enfatizou uma abordagem sócio-histórico do cuidar numa retrospectiva da forma do cuidar, entre os anos de 1956 a 2001, do cuidado laico ao profissional uma fase de lutas e resistências ao poder médico. O artigo A-09 faz referência ao cuidar no centro cirúrgico entre os técnicos e a enfermagem como o todo. E o artigo A-10 ao cuidar do idoso.

Quanto à categorização dos trabalhos no sistema Qualis Capes, observa-se no gráfico 01 que $40 \%(n=04)$ dos artigos se classificam na categoria A. Contudo, nenhum deles encontra-se na categoria A1, a mais elevada. Logo em seguida, as categorias B1 e B3 concentram juntas 60\% $(\mathrm{n}=6)$. A qualidade dos dados pesquisados é atestada pela predominância dos periódicos nas categorias mais bem avaliadas pelo Qualis Capes.

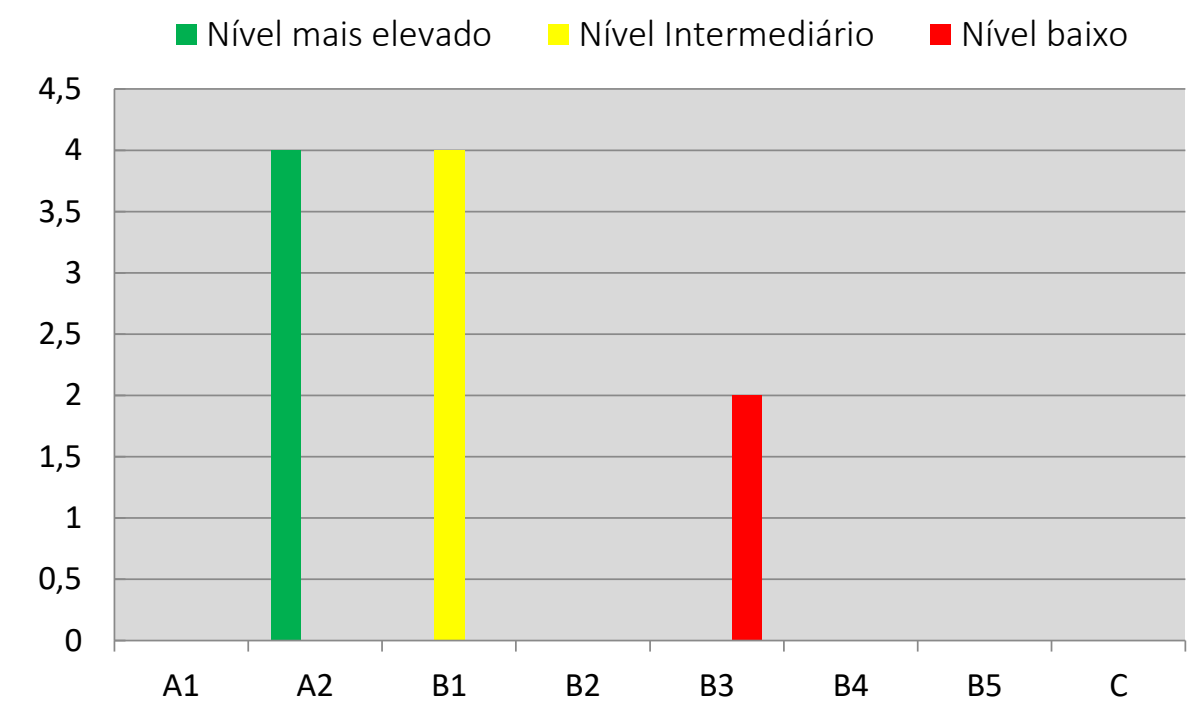

Gráfico 01: Classificação dos estudos no Qualis CAPES.

Quanto ao nível de evidência, verifica-se o nível IV em 90\% dos estudos encontrados e logo em seguida o nível III (10\%),conforme apresentado no gráfico 02. Portanto, dentre os selecionados predominam estudos descritivos com delineamento não-experimental como pesquisa descritiva correlaciona e qualitativa ou estudos de caso. 


\section{Nível de evidência}

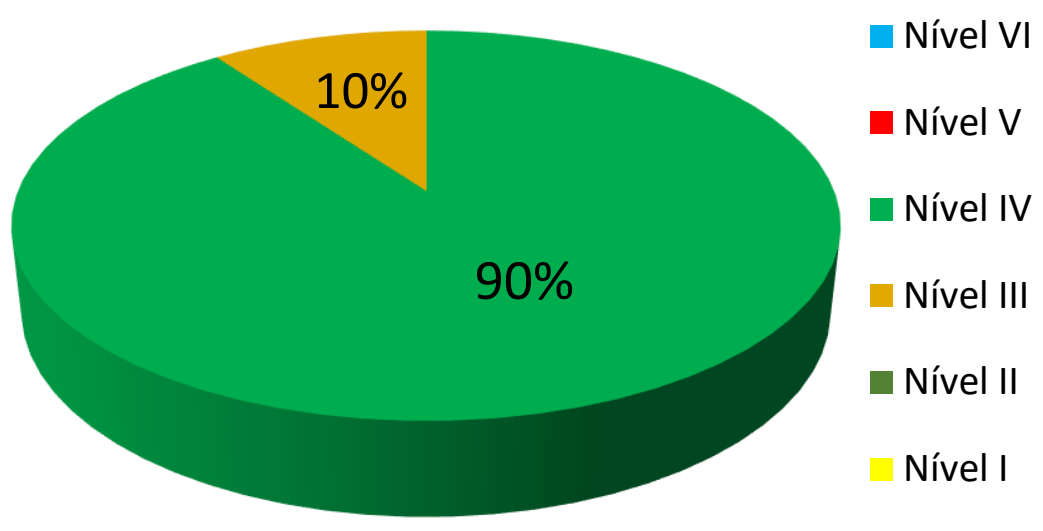

Gráfico 02: Nível de evidência.

Em relação ao tipo de estudo, observou-se a frequência de quadro deles. Conforme o gráfico 03. Verifica-se a predominância de estudos descritivos com abordagem qualitativa $(70 \%)$.

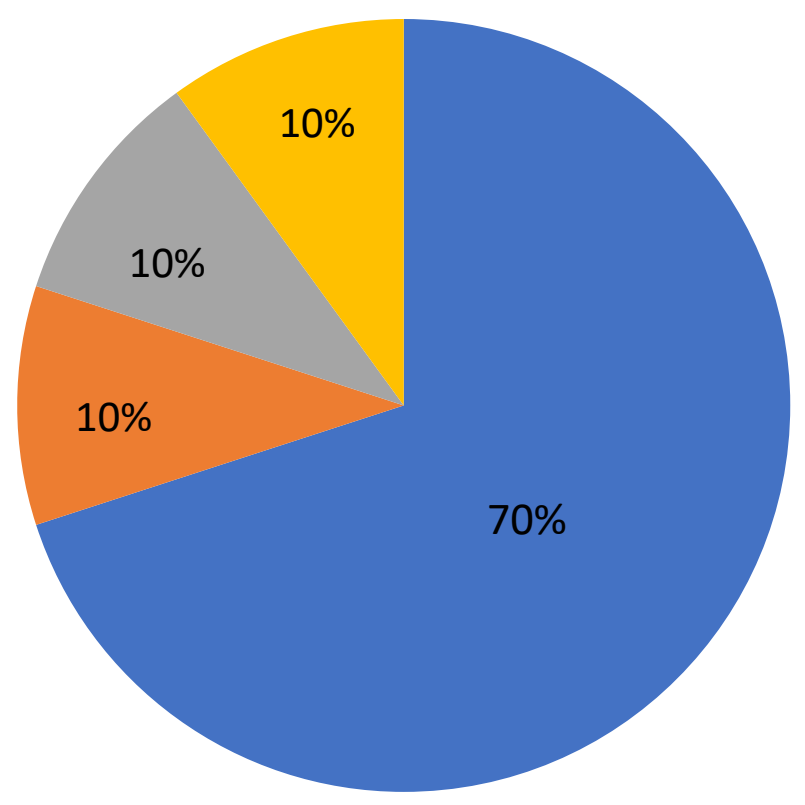

Descritivo com abordagem qualitativa

Descritivo exploratório

- Pesquisa Quantitativa com abordagem sócio-histórica

- Teoria fundamentada em dados

Gráfico 03: Tipos de Estudo. 


\section{Considerações Finais}

O estudo possibilitou a síntese de diversas formas do cuidado, como também a relevância que se apresenta visivelmente quando é feito um tratamento efetivo, ou mesmo, na prevenção e na promoção de uma vida saudável.

Ademais, ficou latente a verificação da missão da enfermagem, que é cuidar para além da patologia, cuidar de forma integral e holística, transcendendo o tempo e a matéria física, com a possibilidade de construir um vínculo paciente-profissional, contribuindo assim numa melhora mais rápida para o tratamento, proporcionando a este, a possibilidade do autocuidado, quando possível. Destaca-se, portanto, a necessidade de mais estudos sobre a temática, objeto da presente revisão, pois, ainda há um déficit em se tratando de literaturas atuais com a temática abordada.

\section{Referências}

APOLINÁRIO, F. H. Significados atribuídos por enfermeiros à assistência que prestam a indivíduos em situação prisional. 2013. 140 f. Dissertação (Mestre em Enfermagem) Universidade Estadual Paulista - UNESP, Botucatu, 2013.

CASATE. J.C.et.al A humanização do cuidado na formação dos profissionais de saúde no cursos de graduação. 2012 Rev. Esc. Enferm. USP.

CASTRO, M.; PEREIRA, W. R. Cuidado Integral: concepções e práticas de docentes de Enfermagem. 2011. Disponível em <http://www.scielo.br/pdf/reben/v64n3/v64n3a12.pdf> Acesso em: 20 de agosto de 2018.

CHERNICHAROI, I. M.; FREITAS, F.D.S.; FERREIRA, M. A. Humanização no cuidado de enfermagem: contribuição ao debate sobre a Política Nacional de Humanização. Rev.Bras.Enferm, Brasília 2013 jul-ago; 66(4): 564-70.

CHRISTOVAM B.P, PORTO I.S, OLIVEIRA. Gerência do cuidado de enfermagem em cenários hospitalares: a construção de um conceito.2012.Rev. Esc. Enferm. USP

CROSSETTI, M. G. O. Revisão integrativa de pesquisa na enfermagem: o rigor científico que lhe é exigido. Revista gaúcha de enfermagem, v. 33, n. 2, p. 8-13, 2012.

GALVÃO, C. M. Níveis de Evidência. Rev. Acta Paul Enfermagem. 2016; 19(2):5. Disponível em <http://www.scielo.br/pdf/ape/v19n2/a01v19n2.pdf> Acesso em: 19 de agosto de 2018. 
HORTA, W. A. Enfermagem: teoria, conceitos, princípios e processo. Rev. esc. enferm. USP [online]. 1974, vol.8, n.1, pp.7-17. Disponível em < http://www.scielo.br/scielo.php?pid=S008062341974000100007\&script=sci_abstract\&tlng=p t> Acesso em: 30 de agosto de 2018.

LAKATOS, E. M.; MARCONI M. A. Fundamentos de Metodologia Científica. 7 ed. São Paulo: Atlas, 2010.

LEITE, R. B.; CORREIA, E. B.; LEITE-SALGUEIRO, C. D. B. L. O olhar social das cadeias de suprimento: uma revisão integrativa da literatura. Revista CESUMAR Ciências Humanas e Sociais Aplicadas, v. 23, p. 149, 2018.

HUMANIZA SUS. Política Nacional de Humanização: PNH. 1 ed. Brasília - DF, 2013. Disponível em < http://bvsms.saude.gov.br/bvs/publicacoes/politica_nacional _humanizacao_pnh_folheto.pdf> Acesso em: 25 de agosto de 2018.

OLIVEIRA, M. A. C. (Re)significando os projetos cuidativos da Enfermagem à luz das necessidades em saúde da população. Rev. Bras. Enferm. Brasília 2012 mai-jun; 65(3): 401-5.

SALBERGO, C., DORNELLES, C. S.;et.al. Significado do cuidado para enfermagem de centro cirúrgico,2015. Reme - Rev. Min. Enferm.

SANTANA, F. R.. et.al. Integralidade do cuidado: concepções e práticas de docentes de graduação em enfermagem do Estado de Goiás. 2012.Ciência \& Saúde Coletiva.

SANTIAGO, R. F; LUZ, M. H. B. A. Práticas de educação em saúde para cuidadores de idosos: um olhar da enfermagem na perspectiva freireana. Reme - Rev. Min. Enferm.;16(1): 136-142 jan./mar., 2012

SAVIETO, M. R; LEÃO, E. R. Assistência em Enfermagem e Jean Watson: Uma reflexão sobre a empatia. Esc Anna Nery 2016; 20(1): 198-202.

SOUSA, S.M.; BERNARDINO, E.; et.al. Cuidado integral: desafio na atuação do enfermeiro. RevBrasEnferm [Internet]. 2017; 70(3):504-10. Disponível em<http://www.scielo.br/pdf/reben/v70n3/pt_0034-7167-reben-70-03-0504.pdf> Acesso em: 19 de agosto de 2018.

SOUZA, G. C.; CABRAL, K. D. S.; LEITE-SALGUEIRO, C. D. B. Reflexões sobre a assistência em enfermagem à mulher encarcerada: um estudo de revisão integrativa. Arq. Cienc. Saúde UNIPAR, Umuarama, v. 22, n. 1, p. 55-62, jan./abr. 2018.

SOUZA, M .L et al. O Cuidado em enfermagem - uma aproximação teórica. Texto Contexto Enferm. 2005, Abr-Jun; 14(2):266-70.

SOUZA, M. T.; SILVA. M. D ; CARVALHO, Rachel. Revisão integrativa: o que é e como fazer. Einstein. 2010; 8(1 Pt 1):102-6

WALDOW, V. R. O cuidado na saúde: as relações entre o eu, o outro e o cosmo. Petrópolis (RJ): Vozes, 2014. 
ZILMER. J.G.V . Et. Al. O olhar da enfermagem sobre as práticas de cuidado de famílias rurais à pessoa com câncer. 2012. Rev. Esc. Enferm. USP.

\section{Como citar este artigo (Formato ABNT):}

BEZERRA SOBRINHO, Aline; VASCONCELOS, Anny Karinny Amaral de; LEITE-SALGUEIRO, Claudia Daniele Barros. O Cuidado Integral como uma Missão da Enfermagem: Uma Revisão Integrativa da Literatura. Id on Line Rev.Mult. Psic., 2018, vol.12, n.42, Supl. 1, p. 790-804. ISSN: 1981-1179.

Recebido: $14 / 11 / 2018$

Aceito: $17 / 11 / 2018$ 